Supplement of Atmos. Meas. Tech., 10, 1783-1802, 2017

http://www.atmos-meas-tech.net/10/1783/2017/

doi:10.5194/amt-10-1783-2017-supplement

(C) Author(s) 2017. CC Attribution 3.0 License.

(c) (i)

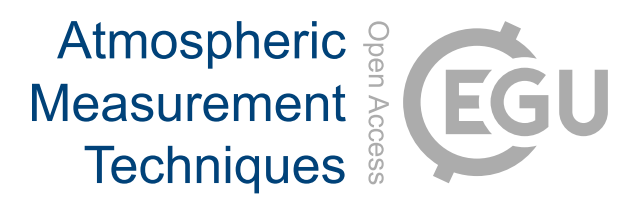

Supplement of

\title{
Optimizing observations of drizzle onset with millimeter-wavelength radars
}

Claudia Acquistapace et al.

Correspondence to: Claudia Acquistapace (cacquist@meteo.uni-koeln.de)

The copyright of individual parts of the supplement might differ from the CC-BY 3.0 licence. 


\section{Distribution of moments for the non-drizzle case study of the 20 November 2014 .}

Here we present in Fig. S1 the normalized distributions of all moments derived for the non-drizzle case of the 20 November 2014.

\section{Impact of fft: additional details}

Here we present the effects of spectral resolution on the different moments for both non-drizzle and drizzle case studies. Doppler spectra derived with 256, 512 , and $1024 n f f t$ and a constant integration time of $2 s$ based on identical time series of raw I/Q data are compared one-to-one for $n_{f f t} 256$ versus 512 and 512 versus 1024 respectively for the drizzle (Fig. S2) and non-drizzle (Fig. S3) case. 

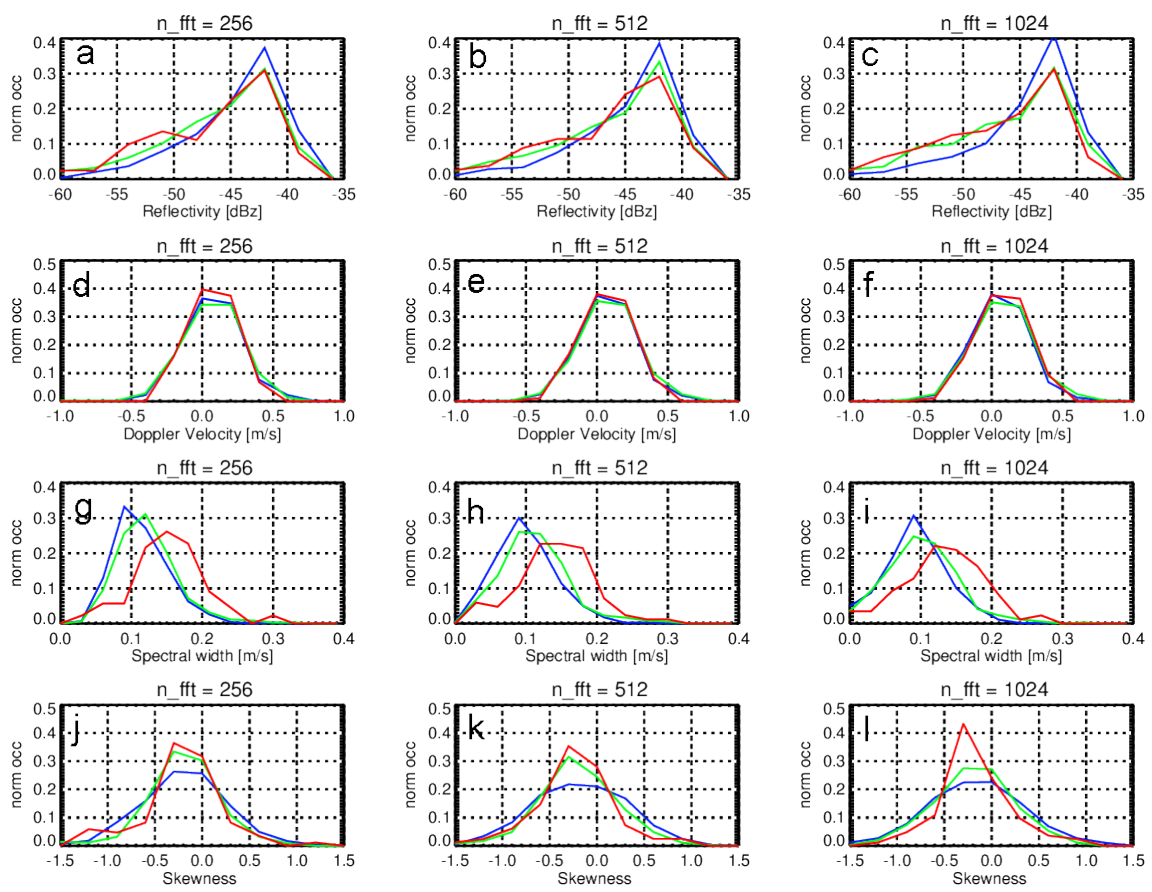

Figure S 1 - Distributions of moments for the case of the 20 November 2014. Each line of the figure shows the distribution for a given moment at the different fft lengths (from left to right 256,512 and 1024): reflectivity $\left(Z_{e}\right)$ on the first line, mean Doppler velocity $\left(V_{d}\right)$ on the second line, Spectral Width $\left(S_{w}\right)$ on the third line, Skewness $\left(S_{k}\right)$ on the fourth line. Different colors correspond to different integration times: red (10s), green $(2 s)$ and blue $(0.4 s)$. 

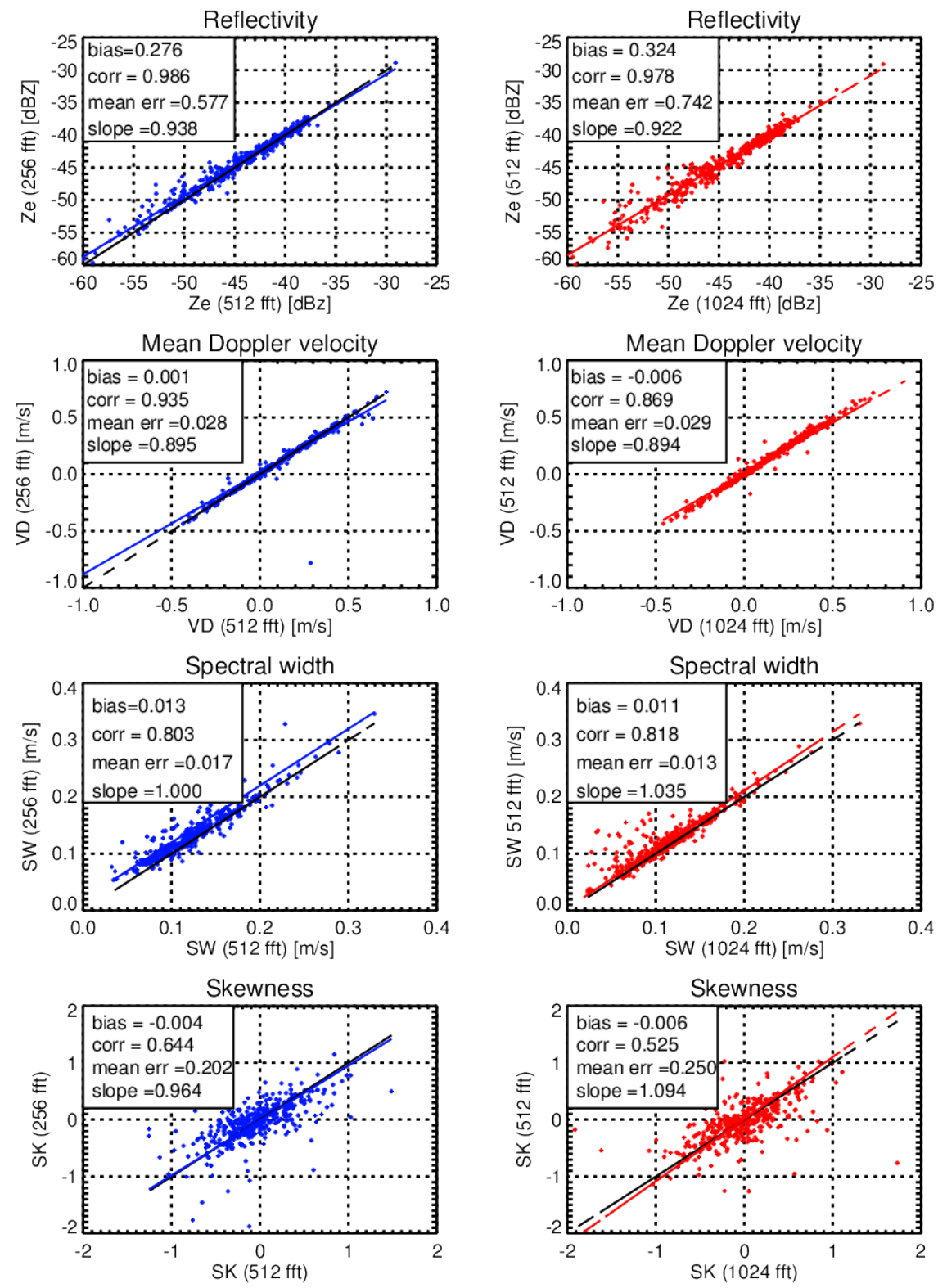

Figure S 2 - Effect of spectra resolution on moments: scatter plot of moments derived at $256 \mathrm{fft}$ length with the corresponding ones derived using $512 \mathrm{fft}$ length for the case of the 20 November 2014. All the spectra are calculated with $2 \mathrm{~s}$ integration time. The left column compares 512 with 256 , while the right column compares the $1024 \mathrm{fft}$ length with the $512 \mathrm{fft}$ length. 

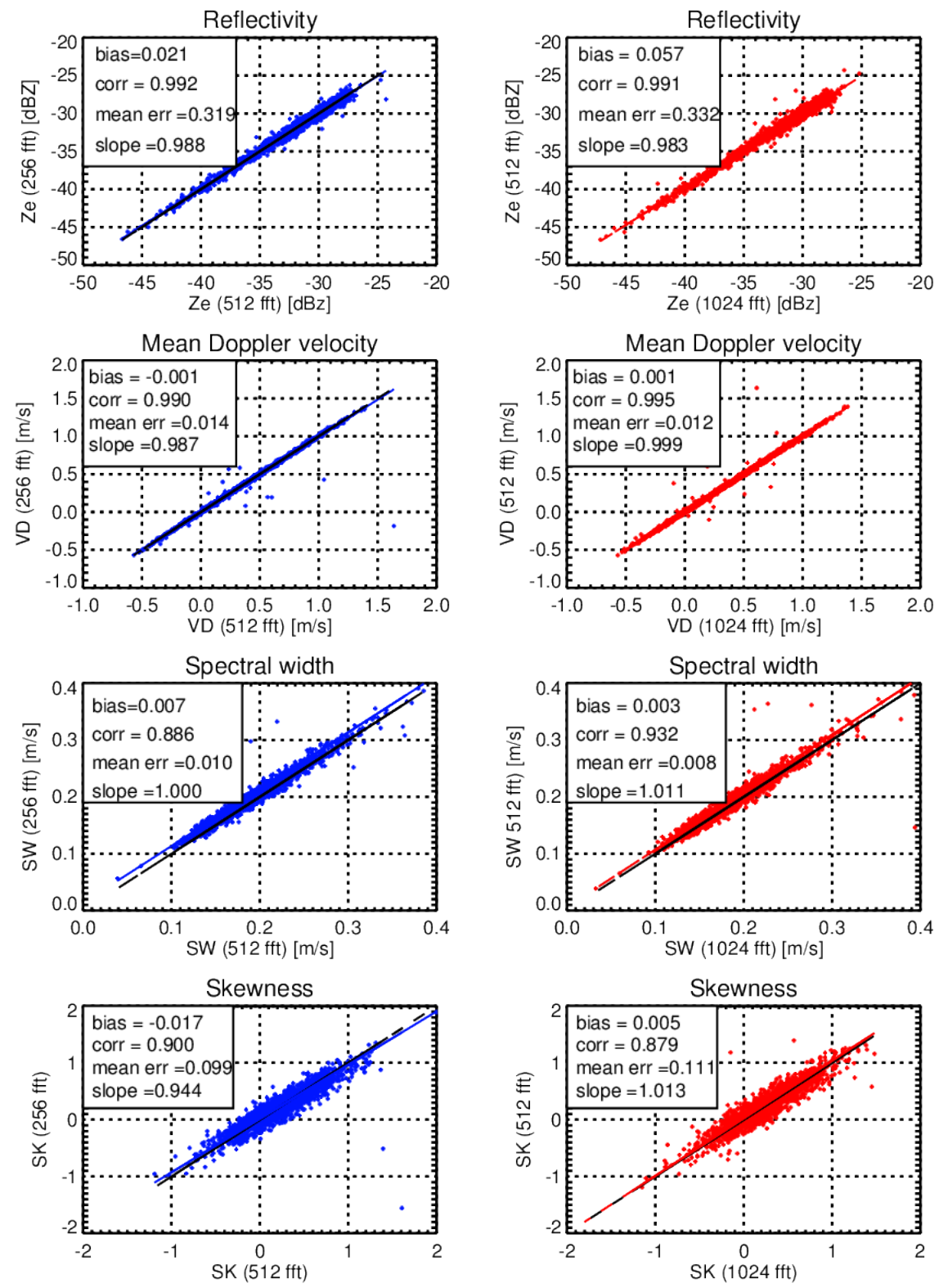

Figure S 3 - Effect of spectra resolution on moments: scatter plot of moments derived at $256 \mathrm{fft}$ length with the corresponding ones derived using $512 \mathrm{fft}$ length for the case of the 24 June 2015. All the spectra are calculated with $2 s$ integration time. The left column compares 512 with 256 , while the right column compares the $1024 \mathrm{fft}$ length with the $512 \mathrm{fft}$ length. 